\title{
Chapter 10 \\ University Intellectual Property Exploitation: \\ Personal Perspectives from the UK and USA
}

\author{
Mark Spearing
}

\section{Moderator}

Good afternoon, good evening everybody. It's time to start our special session. Thank you very much for joining us today, especially I would like to express our greatest thanks to the British Embassy Science and Innovation network, thank you very much. I am responsible for research coordination and administration at Keio University. I am also responsible for IT management and technology transfer for Keio University to industries. The professor over there is my boss who is General Director of this headquarters.

Today we invited Professor Mark Spearing as a speaker who is Pro ViceChancellor (International) at the prestigious University of Southampton in the UK. Today, his title is University Intellectual Property Exploitation: personal perspectives from the UK and USA.

As details of his background will be shown later in the lecture. He has wide and brilliant experiences in universities in the UK and USA. I expect to learn many things and share them among us. After his speech, we would like to have questions from the attendants. Now, we are ready to start. Please go ahead, Professor Mark Spearing.

\section{Professor Mark Spearing}

I would like to speak loud enough and clearly enough that I don't need a microphone. If that's not the case, please let me know. I will do my best.

Thank you very much Hatori-san and Professor Hishida for the invitation to come and join you today and to give this seminar. I am sorry; I will not be back here

Electronic supplementary material The online version of this chapter (doi: 10.1007/978-4-43154306-0_10) contains supplementary material, which is available to authorized users.

M. Spearing $(\bowtie)$

University of Southampton, Southampton, SO17 1BJ, UK

e-mail: spearing@soton.ac.uk 
in September for the rest of the workshop on this topic. I hope I can contribute to it by the talk I will give today.

I have a very high opinion of Keio University because I had the pleasure of working with your Professor Norihisa Miki when we were together at MIT. When I found that he was coming to Keio for a position, I did some research on this place. It is very fine establishment, so I am very honored to be here today. And I would also like to add my thanks to Kevin Knappett and his team at the British Embassy for all the arrangements they have made for my visit to Keio today as well.

I am going to talk about University Intellectual Property Exploitation and I should say that I feel a little bit of a fraud in doing so because I have no professional qualifications in intellectual property exploitation. But I have worked in the university sector for a number of years. I have developed some views of how it operates and I have worked with start-up and, spinout companies. I also have a few patents to my name. Throughout my career I have consistently worked with larger companies, so I feel that I have some qualifications.

In part my invitation by Professor Hishida and Hatori to be here today came from a workshop at the British Embassy in January where I learned a lot about what was happening in Japan regarding the changing nature of the relationship between Japanese universities and industry. I think there are possibly many commonalities with what has happened a while ago in both the US and UK, so there may be some things to be learned regarding what has happened in the different cultures.

I am going to share my personal perspectives and I will invite questions. I will leave time for questions at the end and if you have some burning issue or you don't understand something I am trying to say, please stop me and I will try and answer during the talk. If I am not interrupted I will talk for 30-35 min and leave 30-25 min for questions. If I am interrupted I will just adjust...

So, where I am coming from is I have had the pleasure of working in three great universities. I did my Ph.D. and have subsequently been back on sabbatical to the University of Cambridge in the UK, spending in total 7 years there. I then spent 10 years on the faculty at MIT as a Professor in Aeronautics and Astronautics. And now I have been at University of Southampton for nearly 8 years. These are three quite different universities in two different countries, but all very, very, very successful at exploiting intellectual property and working with industry. You are probably more familiar with Cambridge and MIT. So, I will spend a little bit of time talking about the University of Southampton which you are perhaps less familiar with and unashamedly it's my employer at the moment, so I should be promoting them to you.

All three have very different models for their success and I will try and briefly describe the models and some key facets of it and make some comments and comparison and contrasting at the end.

In putting this talk together I've had input from colleagues: Prof. Phil Nelson is my colleague and fellow Pro Vice-Chancellor, responsible for research and enterprise, which is perhaps close to professor Hishida's role. Don Spalinger, you might infer from the name is an American who works at Southampton. He is the Director of Research and Innovation Services. 
Tony Raven was the former Director of Research and Innovation at the University of Southampton. He now has the equivalent role at Cambridge University.

I will give some overview of the University of Southampton. I will talk about working with large established businesses and experiences in the key places and then talk about spin-out companies and the exploitation of intellectual property through creation of the company and then try and draw it together with some lessons learned at the end.

Please stay with me for maybe $5 \mathrm{~min}$ as I tell you something about the University of Southampton. Like all Twenty-First Century organizations, we have a mission statement. This is ours: "Through education, research, innovation and enterprise...." This is the core of our institution's mission statement that we will provide opportunities that transform the lives of our students, our community, society and the economy. This is the mission statement of our university.

Intellectual property and its exploitation run through that mission statement. It's in the blood of our institution. It's in the blood or the DNA of MIT and actually increasingly of Cambridge, which despite its 800 years of history is a very innovative place and it has been for quite a long time. I also say we are a university with global ambitions. We are not looking just to achieve those aims of our mission statement in the UK or in the south of the UK where we are located, but we expect to have an impact globally and I think that this is probably true of the Keio University, it's certainly true of MIT and Cambridge as well.

My job as the Pro Vice-Chancellor or the Vice-President responsible for International Affairs is to see if we achieve this global ambition. Just a little bit about Southampton. We are currently ranked 75th by the QS World University Ranking. We are member of the Russell Group of prestigious research-intensive UK universities. We've got strength across a wide range of subject areas; in engineering which is where I am from but also in medicine and healthcare and in humanities subjects.

In the UK we are medium-sized university, a bit smaller than Keio, between 22,000 and 23,000 students. The majority, about 18,000 of those are undergraduates, the remainder are postgraduates.

This is a big year for us; we are 60 years old. This picture shows the Queen of the United Kingdom, presenting a Queen's Anniversary Prize for Higher Education to our Vice-Chancellor, President of the University and another colleague (Fig. 10.1). We received this honor, for our work with high performance sport We have a history of working with Formula 1 teams, Ocean Racing Yachts, including the America's Cup; more recently British Olympic athletes. The Olympics are in London this year so we are expecting more success.

Of the last 20 gold medals won by British athletes, 15 have been sports that we provided support for, including cycling and rowing and sailing and increasingly swimming. Wind tunnel aerodynamic testing and design and also hydrodynamics is our contribution.

We are underpinned by world-class facilities, super computers, a world-class clean room that's opened fairly recently. Also a Life Sciences Institute. We are making big investments, totaling $£ 100$ millions 


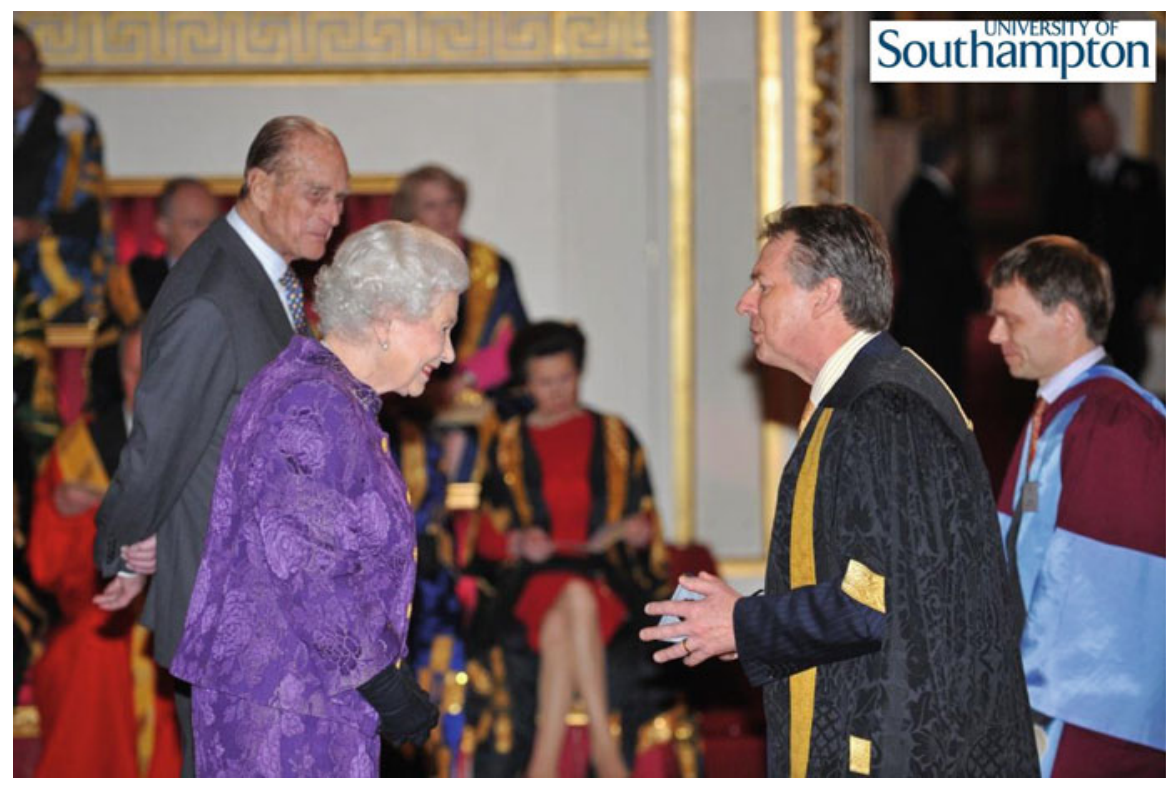

Fig. 10.1 Celebrating 60 years of excellence

We also have a Science Park which for the current discussion is important. We have about 50 companies in this Science Park, mostly small companies and few larger ones. The key part is the taking the basic science ideas into spinouts and then turning it into something bigger and more successful.

These are just some of the facilities and achievements (Table 10.1). Ultimately it is all about people, so I put this slide in. These are some students in our wind tunnel working on an America's Cup yacht (Fig. 10.2). We are a research intensive university; we are a research-led university. Our education includes research and all of our students get an exposure to research. This is really important because fundamentally we are in the ideas business. It's about people having ideas and then following them through.

One of the most impressive things I encountered at MIT was that I would host tables at undergraduate induction. On the first evening undergraduate students spent at MIT they would be come to a large dinner at which academic staff would host a table of ten students. One thousand and fifty students came to MIT so there were about 105 of these tables, each with a member of academic staff, a faculty member on it. The main objective was to get undergraduates to talk to members of academic staff so they felt they could ask questions. As part of that, we would ask them questions and every year when I did this I would ask "so, why did you come to MIT? What do you hope to be able to do when you leave MIT?"

I was struck by the number of students who would respond "I want to have an idea to start a company or to make a product that will make me very rich," which is the very essence of "The American dream." We don't get that quite in the UK, at 
Table 10.1 World-class centres and facilities

Our $£ 3$ millions supercomputer is the fastest Microsoft Windows-powered computer in Europe Groundbreaking nanotechnology and optoelectronics research takes place in our $£ 100$ millions Mountbatten Building, equipped with state-of-the-art clean rooms

Our purpose-built $£ 47$ millions Life Sciences Building is the hub for our Institute for Life Sciences

Our extensive wind tunnel complex is used by Formula 1 teams and UK Sport for aerodynamics testing

We are hosting a new X-ray crystallography service to support and develop research excellence in chemistry, biochemistry and the physical sciences

The University of Southampton Science Park provides a home for established international companies as well as the facilities and support necessary for start-up and early stage enterprises

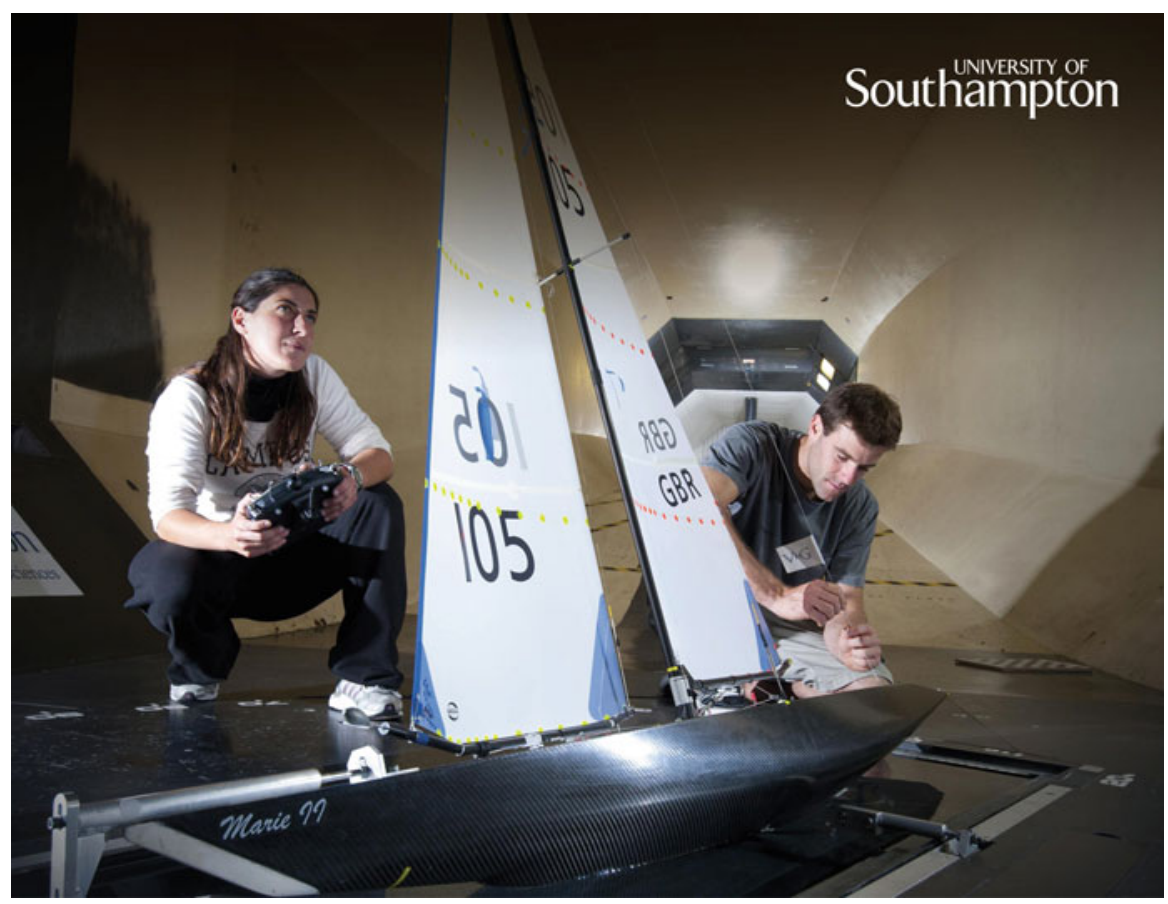

Fig. 10.2 Developing tomorrow's experts

Cambridge or Southampton, but actually having students who think from a very early stage that they are going to have an idea that's going to change the world, is very powerful and that helps it go through the lifeblood of the institution that you are going to do this. You are going to be thinking about having an idea whether you are an undergraduate or Ph.D. student or faculty member.

I also put this in. We own a campus in Malaysia, which is true to our ambition of going global and this will be a research-led campus. This reflects a very strong 
belief that Asia is a very exciting place to be with a lot of ideas coming through, plus this is an attractive place to be. This slide shows our city-we are a large port in South of England, so this is container ships in the port of Southampton at night (ESM, p.16).

We have a number of doctor training centers, Ph.D. education and increasingly in applied fields; fields that the next generation transportation system, complex system simulation. It's not just about discipline, it's about bringing several disciplines together, including the social sciences.

We work in music, we're very strong in music. This is an activity of the medieval music. I have no idea if there's any commercial outcome of this but I do believe that it is really important to open your mind to different disciplines.

These are the some of the things we are working on next generation Optoelectronics. I saw a very exciting work in Professor Koike's lab here on polymer fiber optics. This is work we are doing to a modest goal of increasing the bandwidth of the internet by a factor of 100. A lot of the very early work in fiber optics was done at the University of Southampton, at our Optoelectronics Research Centre.

We are also working through combinations of our Health Sciences activity and electronics and computer science on helping people rehabilitate people who've suffered stroke, debilitating cardiovascular injury.

Now we will get on to the main part of the talk. Remember I'll talk initially about working with big businesses, existing industry and then I'll go on to talk about startups and commercializing ideas in this way. We work with a number of large companies currently including Rolls-Royce who make many of the world's aircraft engines. We have a number of models and I'll talk about the models a bit later.

We are recognized as being the leading university for collaborations with industry. We are ranked second in the UK for our work with small and medium-sized companies, which are notoriously difficult to work with, for a whole variety of reasons. We are very good at this and I will try and explain some of the reasons why. A part of this is a number of partnership models and we'll expand on that later.

These are some of the companies we worked with. Many of them are global, multinational companies. You will recognize the names, Microsoft, IBM, Ford, GlaxoSmithKline. Jaguar Land Rover used to be British is now part of the Tata group, so truly international, Rolls-Royce, etcetera; a lot of companies, a lot of different sectors, although many around engineering.

We are also very good at commercializing research excellence through spinouts. This is a report, produced by a consulting firm, Library House, which is very flattering to our success in generating spin outs. This is a quote, from Doug Richards, the company's CEO, he is an American:

"Perhaps the most striking example of this is Southampton University comes third in this analysis despite being ranked over 100 places lower than both Washington and Wisconsin in the Shanghai Jiao Tong Ranking system. They are rated with Stanford and Cambridge." For some reason MIT doesn't feature on this rating. I think that's because MIT is very, very, very well funded. This is about the efficiency of spinouts. 
Let me get back to big business that will give you an insight into my university, University of Southampton and its success with large companies and small companies.

These are some thoughts about why there are differences between the UK and the USA. I am very aware that things are a bit different in Japan. I have been asking questions on this visit and when I was here in January to understand a little bit more of why, so if you don't ask me questions, I'd be interested to ask you some questions around these issues.

There are lots of reasons why big companies work with universities. In my experience and that of colleagues I consult with, the single biggest reason why companies work with universities is to recruit employees. Access to cutting edge research and technology is also a key, obvious attractor. Leverage of funding is also a key consideration in deciding to work with a University. In the USA and in Europe, this notion of the leverage funding; industry only has a certain amount of money to be spent on R\&D. If it can get government and universities to contribute to that, universities will by putting people in, and time in government, that makes their limited resources for R\&D go further. Increasingly in the UK and USA, our industries do not have the large corporate research labs. They view these as expensive and ineffective, increasingly they are looking to gain knowledge and IP in a much more distributed way, by partnerships and acquisition (of IP) with universities as a key element of their "knowledge supply chain."

There is also symbiosis with industry wanting academia to play a role in working with government and with regulatory bodies, as a neutral arbiter to shape policy standards regulation.

On the negative side universities should not view industry as open checkbook, it does not work like that. There has to be a clear mutual benefit and understanding for the relationship to work. There is also the issue of accessing and sharing research facilities. Large research facilities are expensive and we don't have many of those left in the UK, so universities are playing a key role in managing several of the research facilities in UK and this follows a similar trend in the US. It's not the case that it will necessarily be more efficient but it means that the company doesn't have to own its own facility and incur the capital and operational costs of doing so. Fairly obviously this all amounts to outsourcing skills and a sharing of risks.

You will often hear in meetings, the reason why industry hates to work with the university. It's important for the university to work with industry so as to have access to developing technologies and to understand what the issues and the difficulties are. However there is a perception that Universities have no sense of urgency. We come looking for industry to have that open checkbook that is just a source of funding and give us the money and don't care about the results. This is an unfortunate perception that needs to be actively overcome.

Certainly, in cases where I have seen success in industry-university collaboration the student, the faculty member or the postdoc all strongly feels part of the industry team. It's really important to understand the needs of industry and Universities can sometimes over value the academic contributions and also overestimate the value of intellectual property. This leads to perhaps the most interesting 
contrast between MIT and Southampton and to some extent Cambridge which is somewhere in the middle. I will say a little bit more about this. At MIT-if you work with MIT as a company, MIT owns the IP, there is no negotiation, no assessment, they own it. The company that works with Southampton and pays for the research, we will give them the IP and we won't haggle over the IP issue. Two completely opposite views for two institutions that are very successful at working with industry. That's one of the conundrums behind my interest in giving this talk in this topic. It's not about IP ownership and I actually have a view that some universities are excessively focused on IP ownership. I gather Japanese universities have been under pressure to have technology licensing offices. At the University of Southampton, we don't have one, we make almost no money on licensing IP to large companies. However, one must note that IP is really important for spinouts, and I will speak more about this shortly.

Going back to working with established companies. It is important that there are no inflated egos; academic prima donnas in the team. It is also very clear that if you are going to work with a company, you must understand what the company's concerns are, what is proprietary, what is the competitive advantage that company has.

These are also cultural differences or prejudices. I won't read through the list, you can read through yourself in front of you. The key is on the academic side to acknowledge these perceptions and the genuine differences and look for ways to bridge that gap. Where I see successful partnerships between big business and universities, these differences are being bridged. They certainly don't act as barriers to the collaboration.

In the US and particularly in the UK, we have a diverse range of partnership models between companies, large and small companies and universities. The diversity of funding models means that regardless of the company and the nature of the work they want done, there's a model that fits or can be tweaked to fit.

For the long term-maybe not over the horizon but at the 5-year time horizon for commercialization, there is sponsored research, for activities where you need the answer immediately, there is the consultancy model. You pay me or you pay a research engineer in the university to work on the problem and get it done. We have knowledge transfer secondments. People from industry come back for continuous professional development. All of these activities help to build relationships. We also benefit from sponsored studentships or just acts of philanthropy. I have heard that Sony and Panasonic have made gifts to Keio to try and underpin the new buildings here, so this aspect of business-university interaction is alive and well in Japan.

This is a not a comprehensive list. It's just to say there are a lot of different ways that universities work with external organizations: research funding, visiting professorship to and from industry or to other universities, secondments, just one-off lectures. Across Southampton and it's true of the Cambridge and MIT, I see all of these happen. No one model will do the trick, there is no one answer. In the UK and US you will hear a phrase university-industry partnership is a contact sport. It's full on, it's people banging into each other all the time and it's important that happens because it's essential to maintaining a partnership, it's maintaining a relationship, it's about seeing enough of the other person. Always talking to them, always letting them know how you are feeling. It's not quite a marriage but it has some similarities. Different 
people work in different ways, so having lots of different ways in which that partnership can be formed and then maintained is really important. So, don't look for just one thing, always look for options that you can build on to sustain the partnership.

This is something that's really important. Traditionally, there has been this gap, the innovation gap between an academic having an idea and thinking maybe it will turn commercial and the commercialization of that product.

This gap — and you may be familiar with the concept of technology readiness levels, this might be around about 3, this becomes 7 or 8 . There is this gap between 4 and 6 where it's just difficult to do. 4 is an initial demonstration, 6 is a prototype that lets you pilot the manufacturing processes and issues such as reliability. In between are the activities required to allow you to turn the idea into a real product that can be mass-produced at scale and reduced cost.

Different countries have different problems. In the UK we have a whole bunch of activities going on. There is the spinout route which is perhaps the most conventional way of bridging it, where venture capital or other investment funding is brought to bear. Although highly visible this can be quite an uncertain route.

In the UK, our research councils have well defined ranges of technology readiness levels; 3 and lower is the realm of the basic science research councils. Beyond this, at TRLs 4-6 we have the Technology Strategy Board, that used to be the Department of Trade and Industry. Their funding is generally granted at a 50:50 cost share between government and industry for activities that have a 3-5 year time horizon.

Just recently, the Technology Strategy Board and the Department of Business Innovation Skills have launched Technology and Innovation Centres which are now called Catapult Centers which are somewhat analogous but different to the German model of Fraunhofer Institutes which have proven to be quite an effective model.

Whatever the answer or the name is, it is critical to have mechanisms that bridge "The Innovation Gap." The mechanisms must take the best research, the most commercially promising research at the purely academic level, and help it through to become commercially important to the university and company.

Some keys to success: I have said that the notion of business-university interaction is a contact sport, to see enough of each other and understand each other well. When you are negotiating contracts that are enabling for the collaboration, you need to know on the university side what's the overall goal. I mentioned the issue of flexibility on IP. We give away a lot of the IP in the UK, certainly the Southampton, but what we get in return is the notion that we've made an impact.

The reputation of our university stands amongst other things on the impact that our research has had. That's not necessarily equal to revenues or share capital. As an example at the University of Southampton, colleagues in our Optoelectronic Research Centre developed the erbium fiber amplifier, which is the technology that literally enables the internet. It amplifies signals going down fiber optics every $50 \mathrm{~km}$. Without that, the attenuation would prevent the internet or fiber optic communication to carry across the Pacific or the Atlantic Ocean. There has to be amplification of the signals. That work was done at Southampton. We have derived almost no revenue from it directly but we have had huge reputational advantageous because we are known as the people who did that. 
It's also important to have contacts at all levels; the technical contact, the student, the engineer and the company but also the senior level, our president, our vicechancellor, our vice-president, our deans, managers at a more senior level, the strategic relationships with our key partners. That's an important facet of the "full contact" nature of university relationships with big businesses.

This shows some of the details of our photonics cluster. This picture shows our new clean room. This shows David Payne who is the guy who invented the erbiumdoped fiber amplifier (EDFA). This has been extremely successful over a period of nearly five decades. This activity alone has generated a dozen spinout companies. As a new example of industry-university interaction we are engaged in an unprecedented activity in the UK. We have partnered with a large established organisation, Lloyd's Register, it used to be Lloyd's Register of Shipping. It's moving 350 of its engineers down on to our campus into a new building. We are moving half of our engineering faculty to be close to them. The idea is this will promote the intense collaboration, commonality of interests that allows the university to work with the company. We are also keen to help small or medium-sized companies who work with Lloyd's Register to come down on to our campus.

Based on that, we are looking to cluster around our activities in marine and maritime and bring other companies in. We are a port city, we have longstanding marine engineering activities but also strength in maritime law, transportation logistics and materials issues such as corrosion and biofouling. We host the UK's National Oceanography Centre, a peer institution to your JAMSTEC. These activities cluster around the marine and maritime sector, with common interests. In order to reflect this we have created the Southampton Marine and Maritime Institute to bring these various activities together along with external partners.

Let me just pause. Are there any questions on what I have said so far?

\section{Male Questioner 1}

One question. You mentioned technology and innovation centers, do these belong to the national organization of something in UK?

\section{Mark Spearing}

The funding comes from the Department of Business Innovation and Skills (DBIS). The one I am most familiar with is the High Value Manufacturing Center, which is actually a distributed activity, so it includes seven sites at existing centers that have brought altogether.

\section{Male Questioner 1}

Who organizes these? Politician or chancellor or who? 


\section{Mark Spearing}

It was a competitive process, so the interested parties bid into it, so, if you want to be part of this-and it's a two-stage process, you submit a proposal. In the highvalue manufacturing TIC, there was quite a political process of bringing together groups who didn't necessarily see it as being in their best interest to work together. This was brokered by the civil servants at DBIS more than politicians.

Let me spend another 10 min talking about the spinout which is I think perhaps in some ways more interesting and perhaps less obvious than the issues associate in working with large companies. In Southampton we have had 11 spin-outs, it's 13 now, over 5 years worth about $£ 200$ million. Four have been listed on the Alternative Investment Market. Other spin-outs have become divisions of larger companies; they have spun out and then an exit strategy is applied. Several of these are based on venture capital funding, so it is critical to manage the link between university folks who are perhaps a bit naïve in venture capital ways, brokering relationships with venture capital and this is the role of the university both to maximize the potential of the intellectual property and also its people.

We do a lot of work with non-university spinouts, a lot of this through our science park and its incubation unit. Overall it's about building an ecosystem, so there is a buzz that it's in the air, it's in the water, it's in the blood. We are always looking to spin out commercial activities.

We were the first university in the UK to work with a venture capital brokering group; the IP Group. We also were a pioneer in the use of Alternative Investment Market in London for the vehicle for initial public offerings of University spin outs. We now have over 50 companies located on our science park. There are some large companies, including Cisco and Merck, with the majority being small and mediumsized companies, mostly spinouts.

Overall this provides the ecosystem and we have two fully occupied incubator units for the companies that have two or three employees and need provision of IT support etc.

So back to intellectual property. I mentioned that MIT is very aggressive in its pursuit of intellectual property. When I was there it filed 350 patents a year and its licensing office has an income of over $\$ 100$ million a year, which is a big operation. It's one of the very few technology licensing offices that actually makes money for its university. A vast majority of those in the USA don't, they actually lose money. They are kind of like a luxury car, it's a prestige thing. That's the MIT model. Cambridge has one of the strictest IP models in the UK, but it's much, much more relaxed than MIT and most other US Universities.

The University of Southampton is just a pussycat by comparison. We only protect IP if there is a clear licensing of the spinout possibility. At Southampton we file less than 40 patents a year, which is about $10 \%$ of MIT's patent activity. We only patent really certain things where we know we are going to spin the company out or where we know there is a big company who wishes to license the technology. And we are very flexible, you give away a lot of that spectrum. Overall we do very well, we've got a huge reputational benefit and we also make a significant amount of money. 
Why are these long timescales for IP pay back frequently over 20 years? Frequently, after the patent has expired which is frustrating. Big wins are big, but pretty rare and clumpy.

MIT has a patent portfolio at any one time of 2,000 or 3,000 patents, each of which is maintained at the cost of tens of thousands of dollar a year. It's really expensive. When I was there, there were only three that were making money but they were making money big time, tens of millions of dollars a year each for those three that were making money.

There is potential for distortion of objectives. The impact is just not about making money. There are other things you may be able to achieve other than just revenue. Sometimes good business-university relations matter more, that's often our experience with big companies. We would like to have long-term relationship with the likes of Rolls-Royce, Microsoft and IBM. We don't want things like intellectual property to get in the way of that. If you go into the TLO model for intellectual property, you need the smoothing funding to keep the licensing operation going, to keep up the maintenance of the patent.

In the case of MIT and to some extent increasingly with Cambridge, this is paid for by their endowment. They can invest in their own technology, they can invest in their intellectual property. MIT currently has endowment that's most of \$10 billion. The University of Southampton has no endowment. This also has the feature that if you go after MIT infringing one of its patents, they can protect it. They can hire better lawyers than most potential licensees which has a really big impact. At the University of Southampton, we can't and we won't do this, which is another reason for not being so protective of our own.

As I said, even in the USA, the majority of technology licensing offices lose money and lose millions of dollar a year to their university but they feel the need to persist with this route. In the UK we don't have a technology licensing office as such. We integrate that with the rest of our research and innovation services. We are very, very careful before pursuing patents.

I can say something about our experience of spinning out a companies. Firstly awareness is key. People are looking for the opportunity, it's in the blood, it's in the DNA. At the University of Southampton, we have Research \& Innovation Services. Some academic or student has an idea and they approaches RIS. Their idea is screened, we have a quite experienced management board with people from VCs or experienced entrepreneurs that play a key role here. If it is promising to file the IP, and obtain Proof of Concept funding which we have a bit of in the university. With this the concept can be refined, tested and the business case prepared.

Often we identify an experienced CEO, sometimes a friend of the university to come in and run the company in the initial stage. The case for investment is present to the University investment fund committee. Southampton Asset Managemented is a holding company for our spinouts. Typically first round funding is sought from the IP group, first round funding is the order $£ 0.5$ million or 50 million yen.

They build a team. At 18 months we go to second phase funding which is probably four or five times first phase funding, i.e. $£ 1-2$ million pounds, equating for pre 
money valuation of 3-5 million. At around 2-3 years another round of funding, getting bigger all the time, depends on the topic.

Somewhere around 5-6 years, we're looking to exit either through Initial Public Offering on the Alternative Investment Market or a trade sale often to a rival.

We are looking to exit at about 5 year and realize a return on our investment. Our experience is that it's very much about the quality of management and having something very early on in the process that is exciting to the potential customer, an early demonstration of focus on that to get through to that 3-5 year point.

Increasingly — so that's kind of traditional, we are in a little bit of recession at the moment so we are not seeing nearly as much IP activity, there is not nearly so much venture capital around the UK. We are increasingly seeing what we call soft spinouts where there isn't the need to have venture capital funding. It's a low capital need, often bootstrap from immediate sales, particularly from services, so we've got a couple of these going quite successfully at the moment.

Dezine Force which uses Microsoft's increasing market for the set of applications, high performance engineering products to help particularly small and mediumsized enterprises do engineering design.

Plexus Design which offers cost-modeling services initially for Rolls-Royce but it's doing this - it provides a services comparing costs of different manufacturing routes and different design choices all sources of cost to the company.

Both of these are doing rather quite well without any venture capital funding. They have turnovers of over $£ 1$ million a year after 3-4 years.

We also at Southampton-unusually we have consulting units. These are units staffed by professional engineering that provide a very important interface between academic activity and industrial needs. They are basically service companies providing consulting. They have the same sort of feel of things like Stanford Research Institute and Georgia Tech Research Institute in the US, but we've kept them in the university. And it could be spun out, we could keep it inside. We've been running these for 40-50 years. They provide very important revenue stream for the university but also a bridging mechanism that allows us to get to know companies well. They sort of fit into the gap between small companies and the University.

Okay, I am going to wrap up. These are some of the things I think I have learned from my personal 20 odds years with a number of institutions. There are some quite different models out there. Actually, the model doesn't matter, all of them can be successful. You have to understand the institutional or perhaps to a great extent the national culture and the American dream is something in America that MIT benefits from but you don't see in the UK. I am sure you don't see it in Japan in the same way, it's something different in the UK.

Cultural factors are really important both institutional and national. Some of these I think really do matter. These are the value based on conducting research within the faculty. It doesn't end with a paper. Nobel Prize is nice but there are other ways it has an impact. And it's important that the system rewards how people are hired, what students expect, that all matter. 
Value placed on behaving entrepreneurially. In all three of the universities I have been drawing on from my experience, there is a value. Everyone knows who is being successful of having ideas, translating ideas that are recognized by big companies or they are spinning out. It matters. It's in the institutional values. It's not suppressed, it's out there.

Universities must show creativity in allowing student and staff to be involved with industry. Secondment models, leaves of absence that go and start the spinout. These things really matter, that they support people doing it. If this support is not there, then the entrepreneurial culture will not develop.

Cultures can change. UK universities have become much more overtly entrepreneurial over the last 30 years. When I was an undergraduate, maybe starting to introduce people to Cambridge in the middle of 1980s, it was sort of whispered, so and so spends a lot of time at his spinout or his consulting companies. We don't see enough of him in the lab or in his office. That's changed. People talk in much more positive terms about people having corporate involvement.

There has been I think in the UK quite a strong cultural change. I think it happened in the US but probably a generation earlier. So, I suspect from what I see that that's the journey that Japan has got and is moving quite quickly on in terms of that entrepreneurial culture.

These are just some slogans. Education really matters but enterprise also gives a root to economic impact. All of the places I have mentioned and this would apply to other Universities, start with a really strong science base, strong university, good people, competitive to get into. All of these things make a strong university that makes it much more likely that there will be impact - entrepreneurial impact on large companies. Thank you very much for your attention. We welcome any questions.

\section{Male Questioner 2}

Thank you for your wonderful talk and I have a couple of questions. First, I want to ask you as a young professor or a young faculty member. It is sometimes really difficult to find a good partner in industry because I don't have any good contacts. Do you have any kind of system to promote that kind of cooperation with industry?

\section{Mark Spearing}

Yes. When I arrived at MIT, I was an even younger assistant professor. It felt to me to be important to work with industry, so I had a motivation. I thought as an engineering academic I should be working with industry. That was my attitude. I really, really, really wanted to work with The Boeing Company. Boeing is a major player in the aerospace industry and I worked in composite materials which are very important to the aerospace industry. I even had a little bit of access to Boeing because there were links between MIT and Boeing.

At first when I went to visit Boeing in Seattle, I thought that they will open their checkbook. I was a new assistant professor at MIT. I must be good and they would want to work with me! No! There seemed to be almost complete disinterest. I was taken to dinner by two senior executives of Boeing; the vice-president of engineering and the 
head of materials and structures. They delighted in telling me how they had just completed the Boeing 777, this was 1994, the 777 was just flying, and it was the first Boeing plane with significant composite material content in the airframe's primary structure. They delighted in telling me- these two senior people- how they were not going to have any composite materials, on their next aircraft. In their view it was too expensive. At the time I felt that the door was shut on me, but I went back and senior colleagues said, "No, no, you've got to persist." They don't really mean it. They will keep doing this. I went to Boeing seven times before I eventually was awarded a research contract. Back then it was $\$ 45,000$ for 1 year. It was not even enough to fund a Ph.D. student and I had to scrape around to fund a student. I had a Master's student and had had a bit of funding from somewhere else. I was being tested basically. I had to go around, I had to find the right people, they had to see that I was persistent, that I kept coming back, that I was willing to engage in that full contract. It took me six times before I made it succeed. By the time I left after 10 years at MIT, I had received over one million dollars of funding from Boeing, leveraged by other funding from other agencies. I had been part of two major research programmes, and saw my research translate into the company's products. I was very much part of the Boeing team and I was very proud. I received an award for being a valued member of the Boeing team, it felt really good. I gained my rewards from persistence, and also from listening. Throughout they were telling me what they were really interested in. I would go away, I would think what I would do and go back. Frequently their interests would have changed. So I kept chasing. Eventually they became familiar with me, and perhaps they became familiar with my suspicious accent, and perhaps they became more confident that I wasn't going to leak their secrets to Airbus. Persistence I think would be the biggest message to anyone. For anyone who has got an idea that they believe in; you've got to keep going!

\section{Male Questioner 3}

If you have a university spinout, if it succeeds, there is no problem, however if it fails, after significant investment, and with many employees, what happens? Will the government or some other agency step into support it after a point?

\section{Mark Spearing}

Thank you for the question. The default position is that market forces are allowed to have there way, and failing companies are allowed to fail and f necessary be wound up or become subject to bankruptcy proceedings. I would take this opportunity to make a couple of other points. Firstly I would observe how individuals are treated in these circumstances and I think that the UK has moved quite a long way in this area. If you read Charles Dickens, the consequences of going bankrupt were that the individual would be consigned to the debtor's prison and might never return. This is no longer the case, but bankruptcy still has a considerable stigma in the UK. Anecdotally, in the USA, it is often stated that the average entrepreneurial millionaire has gone bankrupt three times before 
they make it. This is probably an exaggeration, but the point is that it is not viewed as an entirely negative outcome and to some extent individuals are judged to deserve a badge of honor. They pick themselves up off the floor and are being persistent and trying again. So long as they can articulate the lessons learned from that failure, in the USA there is actually considerable admiration of people who fail and are willing to go back at it. I believe that the UK is on a journey towards that type of view.

In terms of financial protection, it is important to choose the right financial model for a startup. Any startup has some element—usually quite a large element—of risk and you need to look very carefully and how that risk is managed financially. Certainly, the venture capital funders are very conscious of that. In the first stage of a start up there might be one venture capital investor involved. In our case we work with the IP Group preferentially. But in the second and third rounds of funding they will usually look for typically three, maybe even five, investors as they want to be diversified. That's the key.

\section{Male Questioner 3}

You have a very strong evaluation committee group or something, is that right?

\section{Mark Spearing}

Yes. For our university that's an important part of the process. We have an entity which we call Southampton Asset Management which is formally a legal company of which I am a director. The majority of directors are external to the university.

The chairman and several directors are entrepreneurs and other members come from venture capital community and are familiar with the financial issues associated with start ups.

In the UK there is a television program called the Dragon's Den where people come in with an idea that they are looking for funding for. It's on television. They have five wealthy individuals who invest real money in front of a television audience. It's a great program, it's great television. It feels a bit like that when the directors of Southampton Asset Management meet with a potential spin out. When our Research and Innovation Services (RIS) see something that's on the cusp of being ready to spin out, the academic or the students involved will come to the board meeting and will present their ideas for 10-15 min and field some questions from the board. We will then come to a decision. Unlike the Dragon's Den it is usually not just one decision about whether to invest or not, the intention is to provide guidance. There will often be several iterations so as to get the value proposition and the core team for the spin out into a position so that they are as credible as possible for obtaining initial funding and success as a company.

This is a really important part of our process. It also usually as an outcome of such meetings that decisions are made regarding investing in patent protection on behalf of the University. It seems to be a good policy for our University. Obviously there are other models that also work well. 
[Multiple Speakers]

\section{Male Questioner 4}

Thank you for a wonderful presentation. My name is Kazukiro Ishida. From the student's opinion, I have a question about why does industry want to work with universities. You said the main point is for industry to identify future employees.

I have some friends who did research with a company as part of their degree studies, but now, after university but none of my friends are working that company now. So, it is difficult for me to agree with your opinion, but I am not sure is it common in the United States or in United Kingdom.

\section{Mark Spearing}

This is a good point. It is certainly not every Ph.D. student working on a company-relevant research project who goes to work for the sponsoring company. This would not work from either perspectives. Students may well want to go to other companies, or stay in University research for longer, and the company will often not want to hire all the students it sponsors. Nevertheless, in my experience, the potential to have first access to bright students working on relevant topics is a major motivation for many companies sponsoring research at Universities. In addition the sponsoring of research gives the company visibility on campus, and other students, not directly involved with the company may be more inclined to seek employment there as a result. I do not have accurate numbers for the fraction of industry-sponsored Ph.D. students who subsequently work for the company that sponsored them. I would estimate that it is significantly less than $50 \%$. Nevertheless, where it does occur, it is a particularly effective method of knowledge transfer to the company.

\section{Moderator}

Last question.

\section{Female Questioner}

I am a researcher from the University of Hokkaido. Thank you for very interesting lecture. Please could you say a little bit more regarding your views on Technology Licensing Offices. If you do not have a TLO, how do you protect your IP or seek commercial opportunities? 


\section{Mark Spearing}

Just to be clear, it is important you have people within the university who looks out for such opportunities, but calling it a TLO, and therefore putting all the emphasis on technology and licensing, implies that's the most valuable part. In my experience in the UK this is a mistake. There are other ways that intellectual property can be exploited so that it has a benefit and generates revenues for the University. The focus on patent filing, generates substantial costs, which are often not recovered by licensing or spin out equity. That said, the TLO model works well for MIT but their TLO could well be the first and biggest TLO anywhere. It's very powerful and they operate at a scale whereby they have a better chance of backing enough of the rare big winners to cover the costs of the much more common patents that only generate costs.

\section{Female Questioner}

My question is I see that your university fund is more focused on the industriallyrelevant research. So do you have a problem of explaining to the society how to balance between the basic research and applied research?

\section{Mark Spearing}

No, but we are successful. So at the moment we are the sixth largest recipient of basic science and engineering research funding in the UK and we also do very well on citation statistics. However, I think in most economically developed countries and developing countries is just not enough. Some of those ideas have to follow through to make a difference to society to keep them relevant.

Actually in a way that's why in UK and US, the big research labs have ceased being really so prevalent because they struggle to justify their impact to the company. Many of the best ideas at Bell Labs and IBM got commercialized by other companies or IBM didn't invest in it. The staff who had the idea went out and founded their own company and IBM did not benefit. Thank you.

\section{Female Questioner}

You mentioned about the collaborate investing issue about collaborating with SMEs can be difficult.

\section{Mark Spearing}

Sure. SMEs are difficult I think the world over to work with because they have people doing multiple things. If you are in an SME, we have several jobs and in 
a large company they have a collaboration manager, someone whose job is to manage a relationship with the university. If you are an SME, that's less likely, so being able to devote the time to the collaboration. Also their timescales tend to be particularly short. SMEs more likely are living quarter to quarter and they make a budget per quarter. If money starts to be tight, we are the first thing to get cut down.

I think there are two contributions. In the UK as a whole there are programs such as Knowledge Transfer Partnerships and Knowledge Transfer Secondments and Kevin who is in-charge of Knowledge Transfer Partnerships, which provide leverage to government funding.

It's preferentially beneficial to SMEs and that's being - and the way those work is a university person, a knowledge transfer associate gets seconded into the company. They are not on the company's budget but they are there. And so it's the university person kind of responsible for the relationship, not the company person. The company person has to manage the person in the next office which is not easy to balance with managing the collaboration.

The other thing that we at Southampton I think are very good at, we have these consulting units which provide a particularly good software professional engineers. They could work to industry timescales where they need to contact the approrpiate Ph.D student at a specialist facility, they can draw it in. But we can provide dedicated professional engineers who can work on the company's problem full-time and they are not like academics who perhaps have to go and teach a lecture or go to a conference and they are not there, just come to us and we will deliver!

Those two mechanisms are really important for Southampton and the UK.

\section{Female Questioner}

What is your motivation-I mean, university people's motivation to work with small companies? I mean I am a business course student and at the same time I running my own small company so I want to know more about this topic.

\section{Mark Spearing}

I think there are multiple and different motivations for working with small companies. At the most basic level, whether it is a small company or a large company, if I consult for you, you pay me, so it's a business transaction. For many of us though it's something a bit more than that. Certainly as an engineer I like solving problems and this is true with many of my colleagues. I derive satisfaction from actually, making a difference-I have worked in industry as well as the places that I mentioned and I have worked a lot with small and medium sized companies. Actually, going in there and providing advice, analysing their problems, even helping design products, you see it makes a difference. It turns into a commercial success, it creates jobs, 
which has a really good feeling. Often with small companies the ability to make an immediate difference than with larger companies As an engineer I can state with certainty that most people get into engineering not because they want to write papers, but that they want to do something that's going to make difference.

If you had the chance to work on a product-I've been around big companies. I have been around The Boeing Company and felt the buzz when a new aircraft comes out. You see that tens and thousands of people who worked on it, it's this huge feeling of creation, of triumph. You've made something, it works, it's a success. That's really a big motivator to many of us. I mean I am not saying we wouldn't want to get paid for the work we provide but equally sharing in that success is a significant motivation. There's something else. It's maybe a little bit more subtle. I know that by working with industry, gaining experience - even as an academic the going into companies, going site visits, I will learn things at the periphery of my interests that I can then bring back to inform my research, to inform my teaching, and be able to motivate students, my undergraduates because I can say, "Hey, I was at this or that company and I saw something really cool. Equally I will be able to say that I was at Keio University and boy, there is a really cool electric car or plastic fibers that's about to become big."

\section{Moderator}

Any other questions? We are running out of time. Thank you very much for this interesting lecture. Additionally, I would like to say we are going to publish the proceedings of this lecture. I therefore am happy to announce that this event is concluded. Thank you very much.

\section{Mark Spearing}

Thank you very much.

\section{END}

Open Access This article is distributed under the terms of the Creative Commons Attribution Noncommercial License which permits any noncommercial use, distribution, and reproduction in any medium, provided the original author(s) and source are credited. 